Article

\title{
Analysis of Drought Characteristics using Time Series of Modified SPEI in South Korea from 1981 to 2010
}

\author{
Seungjong Bae ${ }^{1}$, Sang-Hyun Lee ${ }^{2, *}$, Seung-Hwan Yoo $^{3}$ and Taegon Kim ${ }^{4}$ \\ 1 Institute of Green Bio Science Technology, Seoul National University, Pyeongchang, Republic of Korea; E- \\ Mails: bsj5120@snu.ac.kr \\ 2 Biological and Agricultural Engineering, Texas A\&M University, College station, Texas, USA; E-Mails: \\ sanghyun@tamu.edu \\ 3 Department of Rural and Bio-Systems Engineering, Chonnam National University, Gwangju, Republic of \\ Korea; E-Mails: yoosh15@jnu.ac.kr \\ 4 Institute on the Environment, University of Minnesota, Saint Paul, Minnesota, USA; E-Mails: \\ taegon@umn.edu \\ * Correspondence: sanghyun@tamu.edu; Tel.: +1-737-346-4704
}

\begin{abstract}
The aim of this study is to analyze the characteristics of drought such as intensity, cumulative curves and trends, based on SPEI (Standardized Precipitation Evapotranspiration Index) at 8 stations in Korea from 1981 to 2010. The traditional SPEI is based on Thornthwaite equation for estimating evapotranspiration; SPEI_th. However, a standard of agricultural water management in Korea suggests FAO Penman-Monteith equation; SPEI_pm. In this study, we analyzed the intensity and trends of drought using SPEI_th and SPEI_pm, respectively, and analyzed the relationship between them. Both of central and southern region, the SPEIs were below -1.0 (moderated drought) for the periods May-August in the representative drought year such as 1988, 2001, and 2008-09. The frequency of drought was higher in southern region than central region. In addition, SPEI_pm showed slightly more intensive drought rather than SPEI_th except for Chuncheon and Gwangju. In 5 stations except for Cheoncheon, Gwangju and Jinju, the cumulative probability that SPEI_pm is below -1.5 was significantly increased from 1981-1995 to 1996-2010. As the results of drought trends, the increasing trend of SPEIs was shown on fall season, and the cumulative probability that SPEI_pm is below -1.5 was also significantly increased.
\end{abstract}

Keywords: drought; SPEI; evapotranspiration; Thornthwaite; FAO Penman-Monteith

\section{Introduction}

Drought is the world's costliest disasters and affects a large number of people every year, for example, average of 6 to 8 billion US\$ is caused annually by global drought (Wilhite, 2000). Droughts are recognized as an environmental disaster (Vrochidou et al., 2013), and several researches has evaluated a considerable decrease in water availability caused by a precipitation deficit (Koutroulis et al., 2011; Rossi, 2000; Wilhite, 2000). In addition, climate change will aggravate the water scarcity (Mishra and Singh, 2010).

In South Korea, paddy fields cover an area of $11,500 \mathrm{~km}^{2}$, which comprises $61 \%$ of the nation's total cultivated area (Kim et al., 2009). The paddy rice is the main food crop and also one of the water intensive crops. However, the precipitation intensity will be increased and the number of raining days will be decreased by climate change (KMA, 2010; Kim et al., 2013). In contrast, the crop water demand will be increased due to the increase of evapotranspiration by a high temperature. Accordingly, the agricultural drought could be getting severe in Korea, and it is required to 
understand characteristics of agricultural drought with consideration both meteorological condition and crop growth at the same time.

There are several definitions of drought based on precipitation, soil moisture, or potential evapotranspiration (Heim 2002; Wilhite and Glantz 1985; World Meteorological Organization 1975; Svoboda et al. 2002). The representative drought is defined to meteorological drought, and it is a period of months to years with below-normal precipitation. The SPI (Standardized Precipitation Index) is used as the general index for evaluating meteorological drought severity. The SPI is based on fitting and transforming a long-term precipitation record into a normal distribution, and this index can be computed for different time scales; symmetric for both dry and wet spells; relates to probability (Dai, 2011). Many researches have been executed to evaluate meteorological drought severity using SPI (Mavromatis, 2007; Loukas, 2008; Dubrovsky et al., 2009).

However, the SPI is based on precipitation only, and there is a limitation for evaluating agricultural drought using SPI because agriculture is the most sensitive field to drought condition and crop growth. Agricultural drought is a period with dry soils that results from below-average precipitation, intense but less frequent rain events, or above-normal evaporation, all of which lead to reduced crop production and plant growth (Dai, 2011). It means that agricultural drought is related both precipitation and crops vegetation, thus the integrated drought index should be required in order to evaluate drought impact on crop vegetation under meteorological drought.

The SPEI (Standardized Precipitation Evapotranspiration Index) was developed for evaluating the agricultural drought severity with consideration of meteorological drought and crop evapotranspiration (Vicente-Serrano et al., 2010). Accordingly, National Drought Mitigation Center (NDMC) developed the monitoring drought system using SPEI (Hayes et al., 1999; Wilhite et al., 2007; Nam et al., 2014). In Korea, several studies have been performed to evaluate drought severity with drought index. The spatial and temporal drought distribution was analyzed by SPI (Yoo et al., 2010, 2013; Nam et al., 2008; Kwak et al., 2013; So et al., 2014). In addition, the impact of climate change on future drought was evaluated in several researches in Korea (Jeung et al., 2013; Rim and Kim, 2014; Yoon et al., 2014). However, most researches focused on meteorological drought but the main problem of drought happened in agricultural area. Therefore, the evaluation of drought severity should include both meteorological factor and crop vegetation.

The original formulation of the SPEI suggested use of the Thornthwaite (Th) equation for estimation of evapotranspiration (Thornthwaite, 1948). A few studies evaluated the drought using SPEI based on Thornthwaite equation for calculating evapotranspiration (Kim et al., 2012; Kim et al., 2013). The evapotranspiration is related to several factors such as temperature, precipitation, wind, and humidity etc. However Thornthwaite equation only requires mean daily temperature and latitude of the site, and it was used due to limited data availability. In addition, the previous research indicated that the Thornthwaite (Th) equation underestimated evapotranspiration in arid and semiarid regions (Jensen et al., 1990), and overestimated evapotranspiration in humid equatorial and tropical regions (van der Schrier et al., 2011).

In Korea, FAO Penman Monteith equation is recommended for calculating evapotranspiration because it uses all parameters that govern energy exchange and corresponding latent heat flux (evapotranspiration) from uniform expanses of vegetation.

Therefore, in this study, the SPEI was modified by applying the FAO Penman-Monteith equation, and characteristics of drought such as intensity and trends were analyzed by applying the modified SPEI to runs theory and MK test. These results were compared to the results calculated by Thornthwaite (Th) equation. 


\section{Materials and Methods}

\subsection{Development of modified SPEI}

Materials and Methods should be described with sufficient details to allow others to replicate and build on published results. Please note that publication of your manuscript implicates that you must make all materials, data, computer code, and protocols associated with the publication available to readers. Please disclose at the submission stage any restrictions on the availability of materials or information. New methods and protocols should be described in detail while well-established methods can be briefly described and appropriately cited.

The SPEI is based on the original SPI calculation procedure. The SPI is calculated using monthly (or weekly) precipitation as the input data (Vicente-Serrano et al., 2010). The SPEI uses the monthly (or weekly) difference (D) between precipitation (P) and the reference crop evapotranspiration (ETo). This difference (D) is the water surplus or deficit for the analyzed month (i) is calculated using:

$$
\mathrm{D}_{\mathrm{i}}=\mathrm{P}_{\mathrm{i}}-\mathrm{ETo}_{\mathrm{i}}
$$

In addition, ETo, is calculated generally using a simple climatic water balance (Thornthwaite 1948), and it is expressed as:

$$
\mathrm{ETo}=16 \mathrm{~K}\left(\frac{10 \mathrm{~T}}{\mathrm{I}}\right)^{\mathrm{m}}
$$

where ETo is the reference crop evapotranspiration, $\mathrm{T}$ is monthly temperature, $\mathrm{I}$ is heat index, $\mathrm{K}$ is the constant, and $\mathrm{m}$ is a coefficient depending on $\mathrm{I}$.

However, in Korea, the Penman Monteith equation is recommended as the standard for calculating evapotranspiration when agricultural water demand for constructing an agricultural reservoir is estimated. Therefore, in this study, the SPEI is modified by applying the Penman Monteith equation instead of a simple climatic water balance. Accordingly, the ETo is calculated using the FAO Penman-Monteith method recommended in FAO paper no. 56 (Allen et al., 1998), which uses all parameters that govern energy exchange and corresponding latent heat flux (evapotranspiration) from uniform expanses of vegetation. Most of the parameters are measured or can be calculated from weather conditions. It requires daily, weekly and monthly meteorological data including air temperature, humidity, sunshine duration and wind speed. The FAO PenmanMonteith equation used for 24-h calculations of ETo and using daily or monthly mean data can be simplified, and it is expressed as:

$$
\mathrm{ET}_{0}=\frac{0.408 \Delta\left(\mathrm{R}_{\mathrm{n}}-\mathrm{G}\right)+\gamma\left(\frac{900}{\mathrm{~T}}+273\right) \mathrm{u}_{2}\left(\mathrm{e}_{\mathrm{s}}-\mathrm{e}_{\mathrm{a}}\right)}{\Delta+\gamma\left(1+0.34 \mathrm{u}_{2}\right)}
$$

where ETo is the reference crop evapotranspiration $(\mathrm{mm} /$ day), the slope of saturated vapour pressure/temperature curve $(\mathrm{kPa} / 8 \mathrm{C}), \mathrm{g}$ the psychrometric constant $(\mathrm{kPa} / 8 \mathrm{C}), \mathrm{u}_{2}$ the wind speed at 2 $\mathrm{m}$ height $(\mathrm{m} / \mathrm{s})$, Rn the total net radiation at the crop surface $\left(\mathrm{MJ} / \mathrm{m}^{2}\right.$ day), $\mathrm{G}$ the soil heat flux density $\left(\mathrm{MJ} / \mathrm{m}^{2}\right.$ day), $\mathrm{T}$ the mean daily air temperature at $2 \mathrm{~m}$ height $(8 \mathrm{C}), \mathrm{e}_{\mathrm{s}}$ is the saturation vapor pressure $(\mathrm{kPa})$ and $\mathrm{e}_{\mathrm{a}}$ is the actual vapor pressure $(\mathrm{kPa})$.

The calculated D values by precipitation and ETo using FAO Penman-Monteith method are aggregated at different time scales. For example, the accumulative difference for one month in a particular year with a 12-month time scale is calculated. The SPEI is based on the probability of the $\mathrm{D}$ series, and the log-logistic distribution was applied for standardizing the $\mathrm{D}$ series to obtain the SPEI. The log-logistic distribution can account for negative values, and it is capable of adopting different shapes to model the frequencies of the D series at different time scales (Vicente-Serrano et al., 2010).

Finally, the SPEI can be obtained as the standardized values of probability distribution function of D series, accordingly to a log-logistic distribution. Therefore, SPEI can be compared with other SPEI values over time and space. In other words, an SPEI of 0 indicates a value corresponding to 50 $\%$ of the cumulative probability of D. The SPEI is a standardized value, thus it can be categorized by dryness/wetness grade (Table 1). 
The SPEI can apply the different time scale such as 1-, 3-, 6-, and 12-month, therefore, it is available to analyze both of the short term and long term drought. However, the agriculture is sensitive to meteorological condition of each monthly growth stage. Therefore, this study estimated 1-month SPEI applying FAO Penman-Monteith equation for ETo, which is SPEI-pm, and compared to SPEI-th that applied Thornthwaite (Th) equation. After then, the trends of drought by the 3-month SPEI-pm and SPEI-th were analyzed using the nonparametric Mann-Kendall (MK) test, which is a rank-based procedure suitable for detecting nonlinear trends (Mann, 1945; Kendall, 1975).

Table 1. Classification of Standardized Precipitation Evapotranspiration Index (SPEI)

\begin{tabular}{c|c}
\hline SPEI value & Class \\
\hline More than 2.00 & Extremely wet (humid) \\
1.50 to 1.99 & Severely wet \\
1.00 to 1.49 & Moderately wet \\
0.50 to 0.99 & Slightly wet \\
-0.49 to 0.49 & Near normal \\
-0.99 to -0.50 & Mild dry \\
-1.49 to -1.00 & Moderately dry \\
-1.99 to -1.50 & Severely dry \\
Less than -2.00 & Extremely dry (drought) \\
\hline
\end{tabular}

\subsection{Drought intensity through runs theory}

Drought characteristics includes various drought condition such as duration, severity, and intensity (Dracup et al., 1980), A probabilistic methodology widely used in drought characterization is the application of runs theory proposed by Yevjevich, 1967, which allows the estimation of return periods of extreme events (González and Valdés, 2006). We applied runs theory for analyzing drought characteristics based on SPEI_th and SPEI_pm. Figure 1 showed the drought characteristics using the run theory for a given threshold level. A run is defined as a portion of time series of drought variable, in which all values are either below or above the selected truncation level; accordingly it is called either a negative run or a positive run (Mishra and Singh, 2010). In runs theory, drought intensity is the average value of a drought parameter below the threshold level, which is measured as the drought severity divided by the duration.

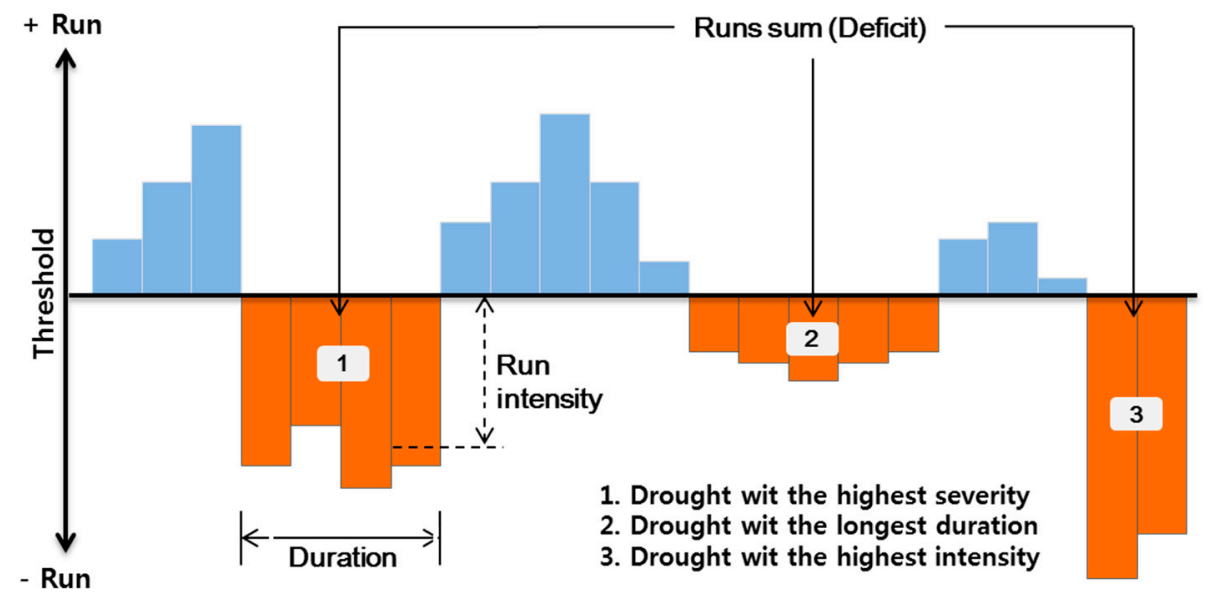

Figure 1. Drought characteristics using the run theory for a given threshold level 


\subsection{Drought trends through Mann Kendall test}

The Mann-Kendall (MK) test (Mann 1945), a rank-based nonparametric method, is applied in this study to detect the existence of trend (Wang et al., 2005). Under the null hypothesis Ho that a series $\left\{x_{1}, x_{2},,, x_{N}\right\}$ comes from a population where the random variables are independent and identically distributed, the MK test statistic is given by

$=\sum_{\substack{\left.i=1 \\-x_{i}\right)}}^{N-1} \sum_{j=i+1}^{N} \operatorname{sgn}\left(x_{j}\right.$

where,

$$
\operatorname{sgn}\left(x_{j}-x_{i}\right)=\left\{\begin{array}{rc}
+1, & x_{j}>x_{i} \\
0, & x_{j}=x_{i} \\
-1, & x_{j}<x_{i}
\end{array}\right.
$$

To avoid the occurrence of equal values, we may add a small uniformly distributed random value in the interval $(0, \sigma / 100)$, where $\sigma$ is the standard deviation of the series. Kendall's s, which measures the strength of the monotonic trend, is estimated by:

$=\frac{2 S}{N(N-1)}$

Kendall (1975) showed that the variance of $S, \operatorname{Var}(S)$, for the situation where there may be ties (i.e., equal values) in the $x$ values, is given by

$$
\left.-\sum_{i=1}^{m} t_{i}\left(t_{i}-1\right)\left(2 t_{i}+5\right)\right]
$$$$
\sigma_{S}^{2}=\frac{1}{18}[N(N-1)(2 N+5)
$$

Under the null hypothesis, the quantity $\mathrm{z}$ defined in the following equation is approximately standard and normally distributed:

$=\left\{\begin{array}{cc}(S-1) / \sigma_{s} & \text { if } S>0 \\ 0 & \text { if } S=0 \\ (S+1) / \sigma_{s} & \text { if } S>0\end{array}\right.$

At a 0.05 (or 0.1 ) significance level, the null hypothesis of no trend is rejected if $|z|>1.96$ (or 1.645). For a series with given $N$, we can calculate its $\sigma_{\mathrm{s}}$ with Eq. (6). At a specific significance level (0.05 or 0.1 ), we know its corresponding critical value of $\mathrm{z}$, accordingly we can calculate the corresponding statistic S using Eq. (7) and consequently calculate the critical value of Kendall's s with Eq. (5).

\subsection{Site description}

Nationwide eight locations in South Korea were selected, and it is shown on Figure 2. Four stations, including the Chuncheon (code: 101), Suwon (119), Cheongju (131) and Daejeon (133), are located in the central region, which is located between 36 and $38 \mathrm{~N}$, and others, including the Daegu (141), Jeonju (146), Gwangju (156), and Jinju (192) stations, are located in the southern region, between 34 and $36 \mathrm{~N}$. Annual mean temperature, and rainfall for the stations were examined during 19812010, and the results are shown in Table 2. The highest annual mean temperature among the target locations was represented in Daegue while the lowest temperature was in Chuncheon. The largest volume of annual rainfall was shown in Jinju near by the south coast of the Korean Peninsula. 


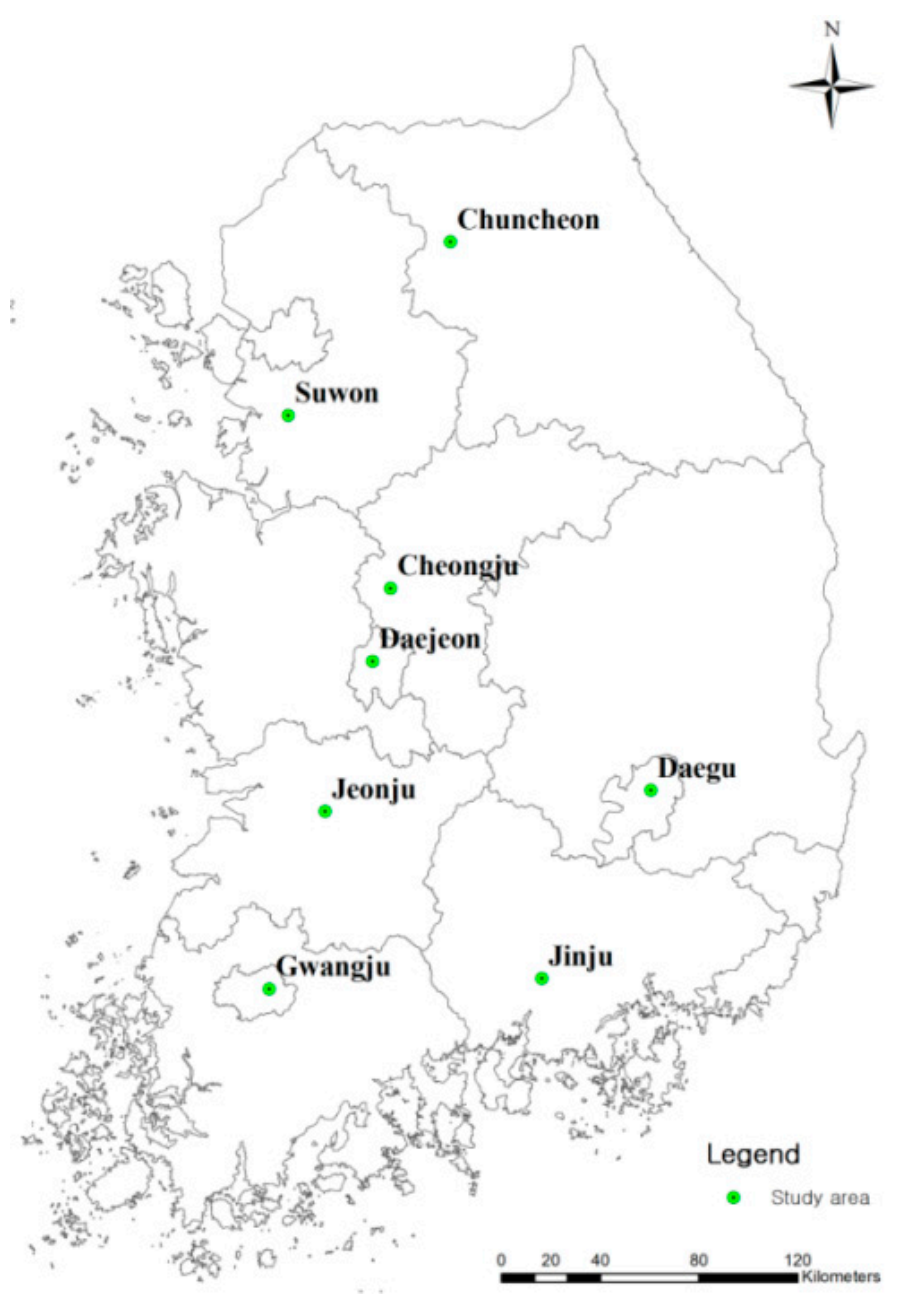

Figure 2. Locations of the eight meteorological stations in this study

Table 2. Climatic characteristics by study meteorological stations

\begin{tabular}{llcc}
\hline \multirow{2}{*}{ Regions } & Stations (No.) & $\begin{array}{c}\text { Annual mean } \\
\text { Temperature }\left({ }^{\circ} \mathrm{C}\right)\end{array}$ & $\begin{array}{c}\text { Annual rainfall } \\
(\mathbf{m m})\end{array}$ \\
\hline \multirow{5}{*}{ Central } & Chuncheon (101) & 11.2 & $1,357.4$ \\
& Suwon (119) & 12.2 & $1,333.3$ \\
& Cheongju (131) & 12.6 & $1,249.8$ \\
& Daejeon (133) & 12.8 & $1,373.9$ \\
\hline \multirow{3}{*}{ Southern } & Daegu (143) & 14.2 & $1,076.1$ \\
& Jeonju (146) & 13.4 & $1,317.7$ \\
& Gwangju (156) & 13.9 & $1,385.7$ \\
& Jinju (192) & 13.2 & $1,523.0$ \\
\hline
\end{tabular}




\section{Results and Discussion}

\subsection{Analysis of seasonal and regional drought in South Korea using SPEI}

During the past 30 years, Korea suffered from the severe drought damage at least once every 58 years (KRC, 2001; Kim et al., 2012). In addition, the moderate drought has been happened annually in the regional and national area, since 1990. The highest agriculture water demand in Korea generally happened from May to August, and the severe drought during this season caused the extensive damage to rice production in 1981, 1982, 2000, and 2001 (Table 3). Accordingly, Korea might be listed as vulnerable to drought, and it is important to understand the characteristics of drought trends using drought index.

Table 3. Status of major drought in South Korea Since 1980's (Kim et al. 2012)

\begin{tabular}{c|c|c}
\hline Year & Drought Period & Major drought regions \\
\hline 1981 & May-June & Southern \\
1982 & January-May & Southern \\
1988 & June-August & Central, Southern \\
1994 & June-July & Southern \\
1995 & June & Southern \\
2000 & February-May & Southern \\
2001 & March-June & Central, Southern \\
2002 & February-April & Part of southern \\
$2008-2009$ & September-March & Central \\
\hline
\end{tabular}

In this study, the SPEI_th and SPEI_pm were calculated as the drought index from 1981 to 2010, and the results were shown on Figs. 3-4. The shaded area in Figure 3 indicates the representative drought events. Both of central and southern region, the SPEIs were below -1.0 (moderated drought) for the periods May-August in the representative drought year such as 1988, 2001, and 2008-09.

In central region, the lowest SPEIs on August were shown in Cheongjuand both of the SPEI_th and SPEI_pm were calculated to -1.6 (Severely dry) in 1998, followed by Chuncheon (-1.6), and Suwon (-1.4). The frequency of drought was higher in southern region than central region. In 1982, 1988, 1994, 1995, 2000, 2001, and 2008-09, moderate and severe droughts were happened in southern region. In 1994, the SPEI_th and SPEI_pm on July were -2.6 and -2.3 (extremely dry) respectively in Daegu. In addition, under -2.0 SPEIs was estimated in Jeonju, Gwangju, and Jinju on July, 1994. These results verified that the simulated SPEIs could reflect the representative drought. 


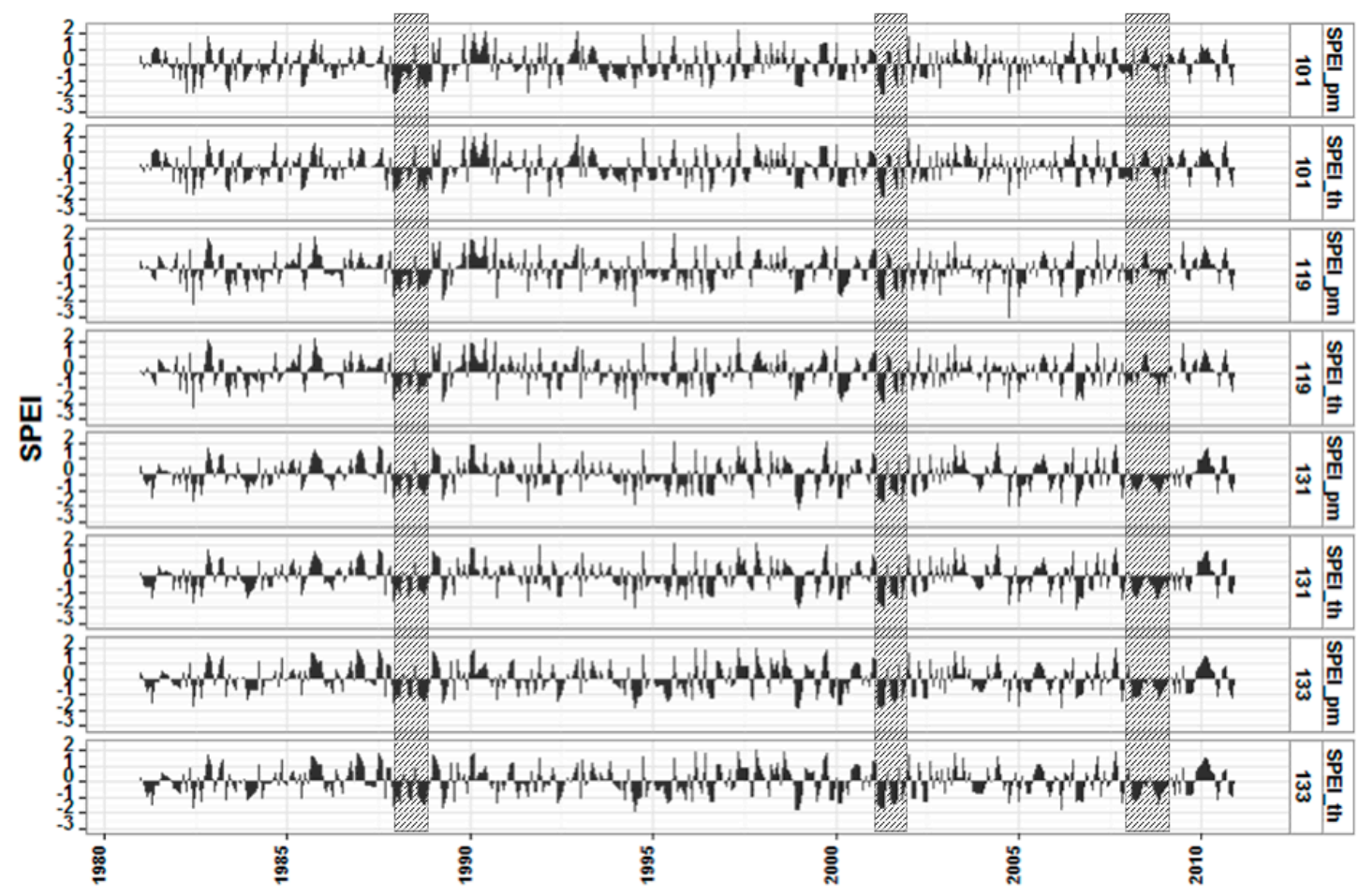

(a) Central region

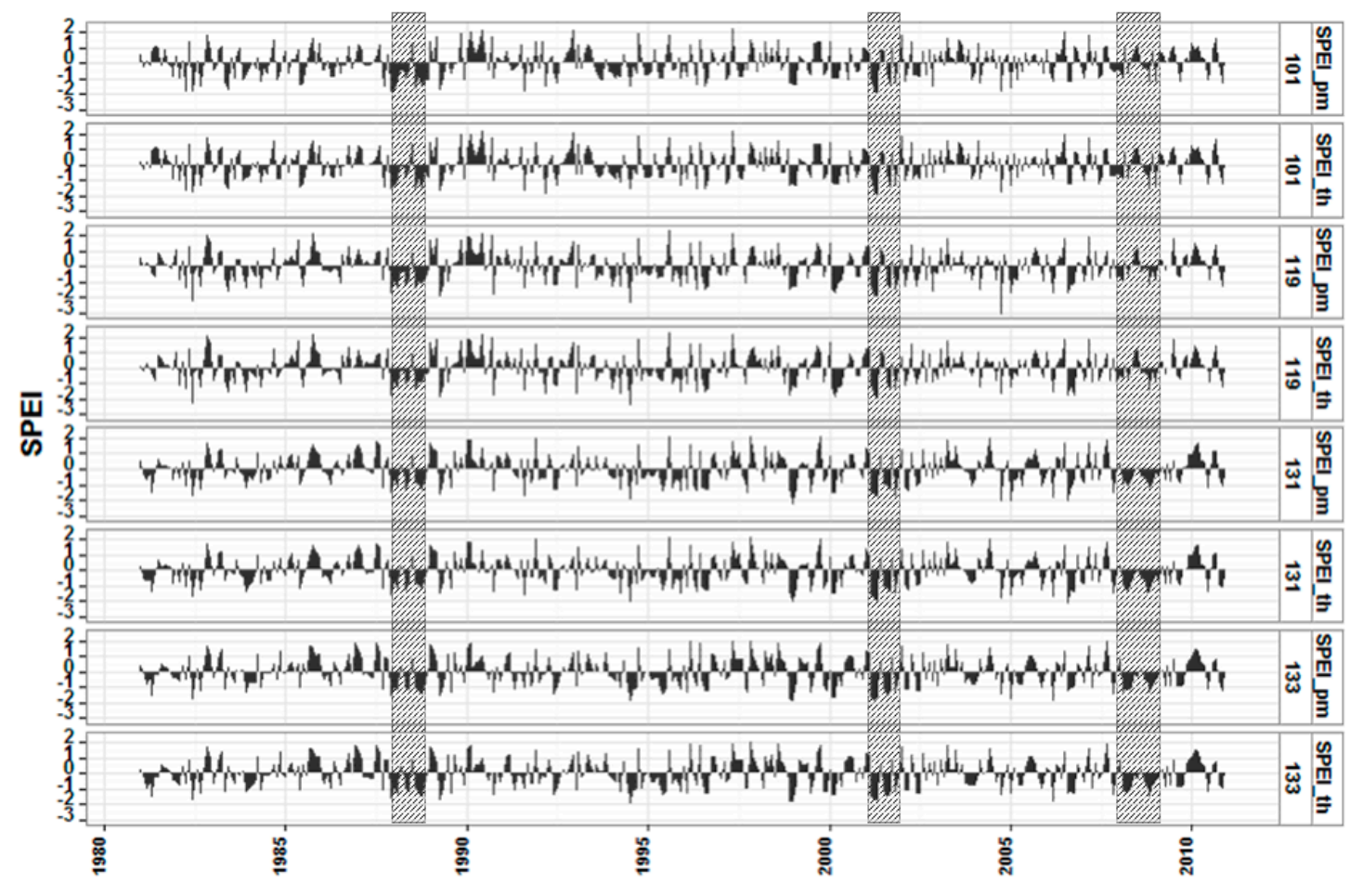

(b) Southern region

Figure 3. 1-month SPEI_th and SPEI_pm from 1981 to 2010. The shaded area indicates the major drought season 


\subsection{Analysis of relationship between SPEI_th and SPEI_pm}

In the Korean peninsula, the meteorological characteristics are classified into four seasons every 3 months: winter (Dec.-Feb.:DJF), spring (March-May:MAM), summer (June-Aug.:JJA), and fall (Sept.-Nov.:SON). Accordingly, the time scale was set by four seasons (DJF, MAM, JJA, and SON) and the relationship between SPEI_th and SPEI_pm was analyzed in each season.

Figure 4 shows 1 to 1 graph between SPEI_th and SPEI_pm. These SPEIs had strong relationship in all months. In MAM season, the relationship between SPEI_th and SPEI_pm was weaker than JJA, and March showed a large dispersion of relationship in the section below 0.0 of SPEI. Generally, March and April might be regarded as the spring drought season in South Korea, thus the application of a single drought index such as SPEI_th or SPEI_pm could give the biased information about drought severity. In addition, October showed the weak relationship between SPEI_th and SPEI_pm, and this result had import meaning in terms of water management because most of agricultural reservoirs are filled with rainfall during October in order to supply irrigation water in the following year. Therefore, a drought in October could affect water shortage in reservoir and irrigation water scarcity in the following year. On the other hand, in wet season (JJA), there was the strongest relationship between SPEI_th and SPEI_pm.

We also counted the number of month whose SPEI was higher than other (Table 4). In Suwon, the SPEI_pm was lower than SPEI_th on JJA but Chuncheon and Cheongju showed the opposite result. In Daejeon, the SPEI_th was lower than SPEI_pm on winter season (DJF) but the opposite result was represented spring season (MAM). These results discovered that the difference between SPEI_th and SPEI_pm varies depending on season and region.

Table 4. The number of months whose SPEI_th (or SPEI_pm) was higher than SPEI_pm (or SPEI_th)

\begin{tabular}{|c|c|c|c|c|c|c|c|c|c|}
\hline \multirow[t]{2}{*}{ Regions } & \multirow[t]{2}{*}{ Stations (No.) } & \multicolumn{4}{|c|}{$\begin{array}{c}\text { No. of months } \\
\text { (SPEI_th }>=\text { SPEI_pm) }\end{array}$} & \multicolumn{4}{|c|}{$\begin{array}{c}\text { No. of months } \\
\text { (SPEI_th<SPEI_pm) }\end{array}$} \\
\hline & & DJF & MAM & JJA & SON & DJF & MAM & JJA & SON \\
\hline \multirow{4}{*}{ Central } & Chuncheon (101) & 49 & 45 & 49 & 44 & 41 & 45 & 41 & 46 \\
\hline & Suwon (119) & 47 & 43 & 40 & 48 & 43 & 47 & 50 & 42 \\
\hline & Cheongju (131) & 44 & 43 & 49 & 44 & 46 & 47 & 41 & 46 \\
\hline & Daejeon (133) & 50 & 41 & 44 & 49 & 40 & 49 & 46 & 41 \\
\hline \multirow{4}{*}{ Southern } & Daegu (143) & 40 & 45 & 42 & 41 & 50 & 45 & 48 & 49 \\
\hline & Jeonju (146) & 46 & 50 & 43 & 48 & 44 & 40 & 47 & 42 \\
\hline & Gwangju (156) & 49 & 43 & 50 & 42 & 41 & 47 & 40 & 48 \\
\hline & Jinju (192) & 48 & 43 & 45 & 48 & 42 & 47 & 45 & 42 \\
\hline
\end{tabular}




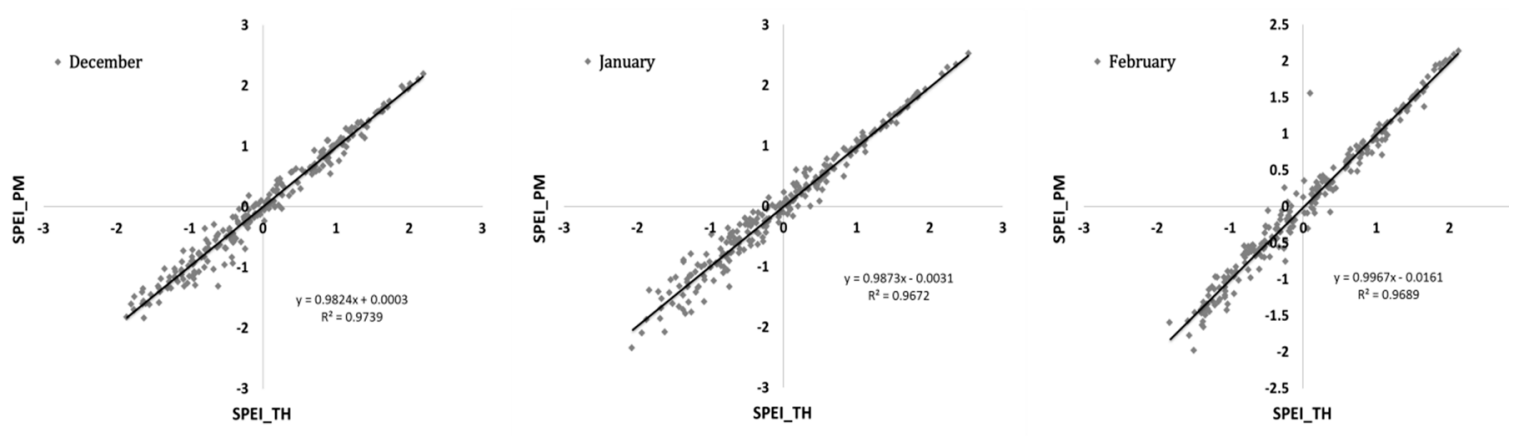

(a) Winter season (Dec.-Feb.:DJF)

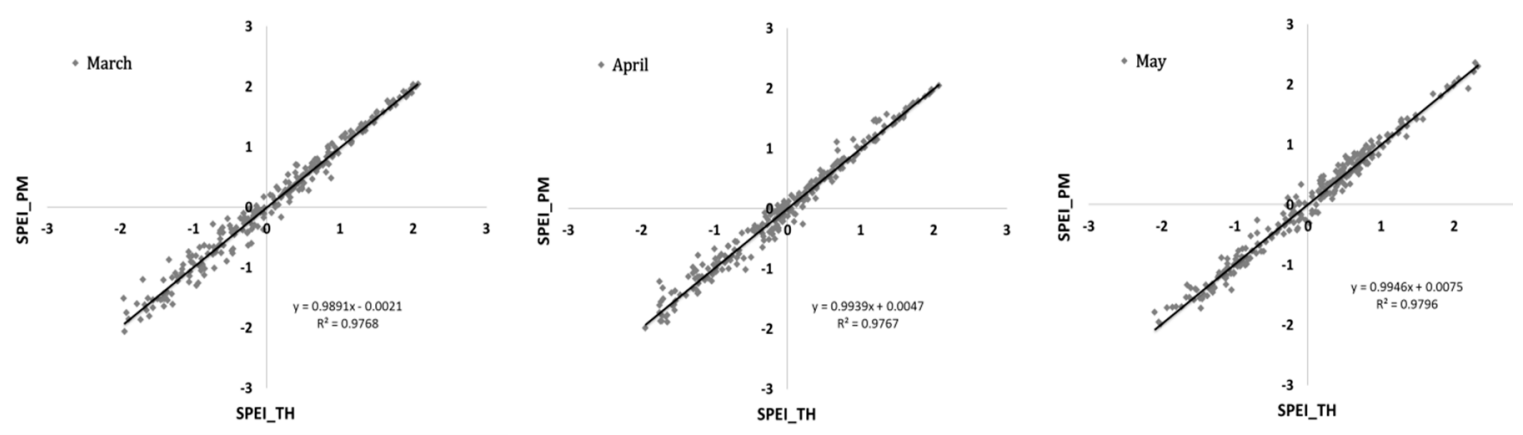

(b) Spring season (March-May:MAM)
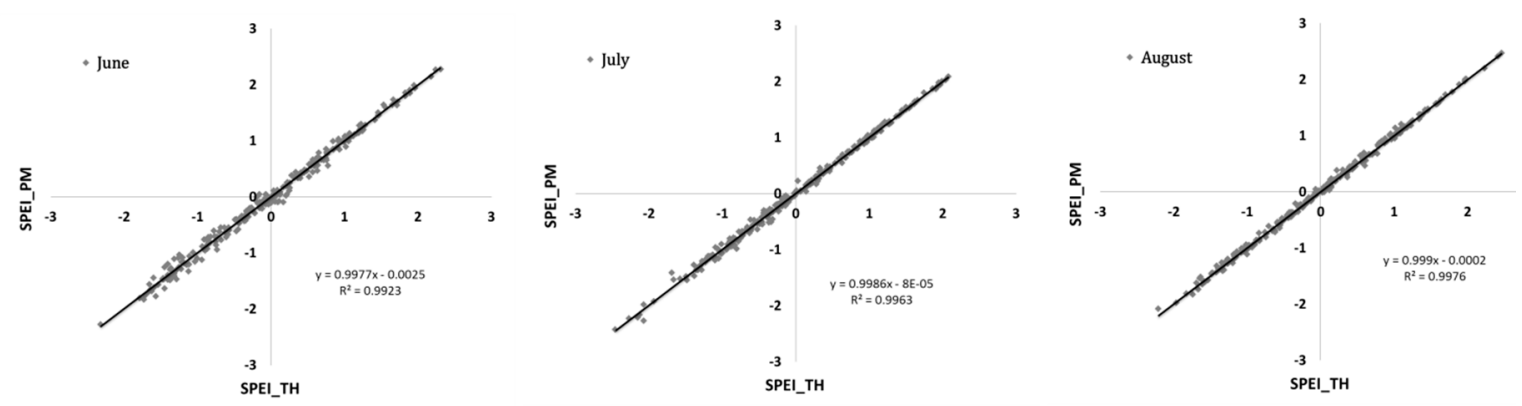

(c) Summer season (June-Aug.:JJA)
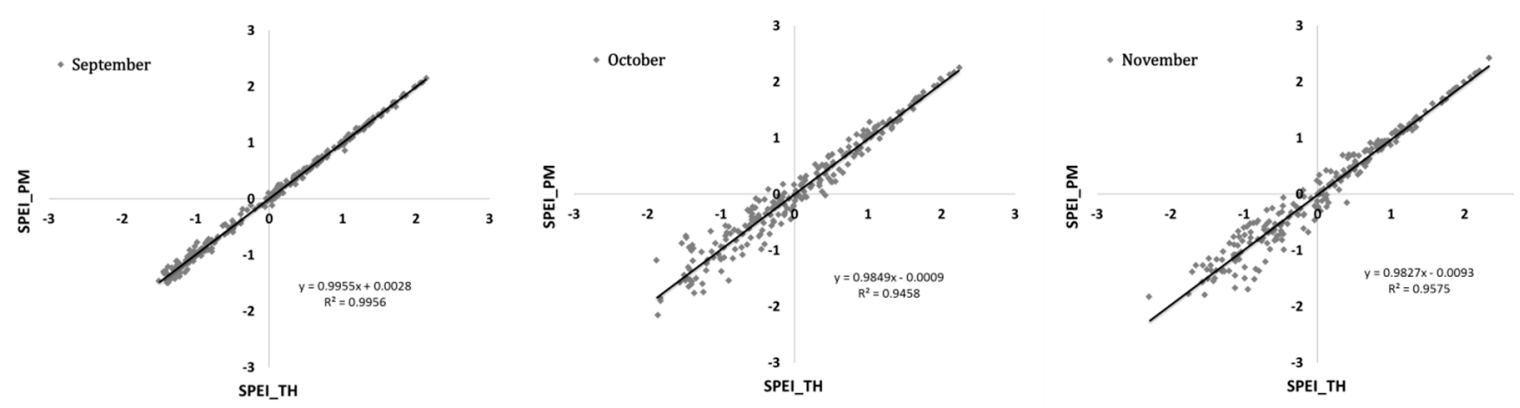

(d) Fall season (Sept.-Nov.:SON)

Figure 4.1 to 1 graph between SPEI_th and SPEI_pm in each month 


\subsection{Analysis of drought characteristics and changing trends}

The drought intensity is the representative characteristic of drought, and it is based on drought severity and duration by runs theory. We set -1 of SPEI as the threshold value for identifying drought condition, and the SPEIs below -1 were used to estimate drought intensity.

Figure 5 indicates drought intensity through SPEI_th and SPEI_pm, respectively in 8 stations. In most of stations, SPEI_pm showed slightly more intensive drought rather than SPEI_th except for Chuncheon and Gwangju. In particular, in Suwon, drought intensity by SPEI_pm was 1.47 but SPEI_th showed 1.41. These results showed that drought identification could be dependent on the method of SPEI even if same climate condition is given.

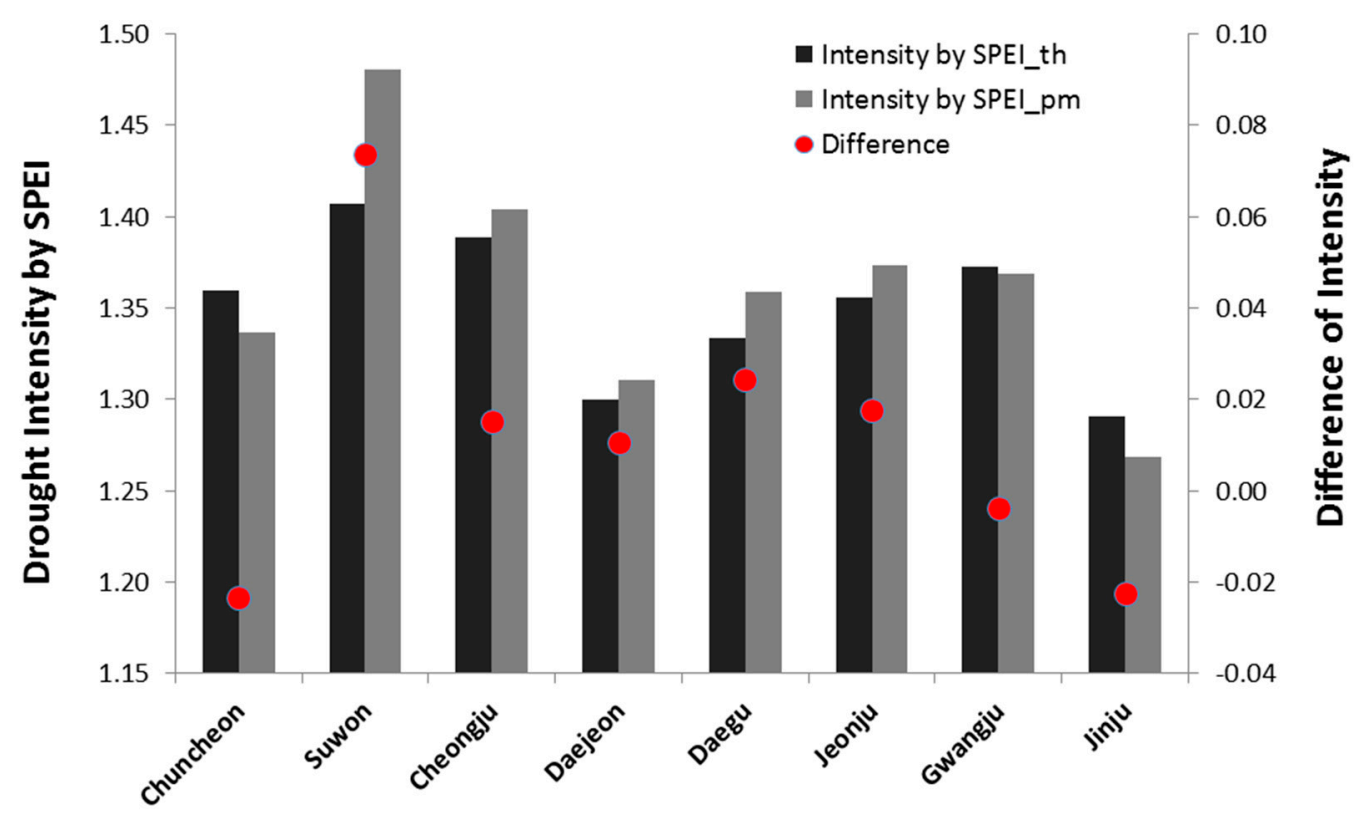

Figure 5. Drought intensity through SPEI_th and SPEI_pm

In addition, the probability of drought occurrence was estimated using cumulative curves of SPEI. Figure 6 maps the cumulative curves of monthly SPEI_pm in two periods (1981-1995 and 19962010). In Chuncheon, there was $7.7 \%$ cumulative probability that SPEI_pm is below -1.5 in for the periods 1981-1995 but it was decreased to $3.7 \%$ for the periods 1996-2010. It means that the frequency of severe droughts was decreased for 30 years.

In 5 stations except for Cheoncheon, Gwangju and Jinju, the cumulative probability that SPEI_pm is below -1.5 was significantly increased from 1981-1995 to 1996-2010. The most increase of cumulative probability was show in Jeonju (4.8\% increase), followed by Cheonju (4.5\% increase), Suwon( $4.4 \%$ increase), Daejeon (3.3\% increase), and Daegu (1.7\% increase). These results reflected the severe drought happened frequently for 30 years.

Table 5 indicates the trends of seasonal SPEIs through MK test. In case of annual SPEI_th, Jeonju showed the decreasing trend statistically at the 0.05 significance level. The trends of SPEI_th varied by season and region. In SON season, 5 stations (Cheongju, Daejeon, Daegu, Jeonju, and Gwangju) had a decreasing trend of SPEI_th at the 0.05 significance level. In MAM season, the decreasing trend was represented in Jeonju but the increasing trend was shown in JJA due to the increase of rainfall. However, the trends of SPEI_th in MAM and JJA were not significant at the 0.05 significance level.

The SPEI_pm showed the similar trends of SPEI_th annually. Jeonju had the decreasing trend at the 0.05 significance level. The seasonal trend of SPEI_pm was slightly different from SPEI_th. In SON season, only 2 stations (Daejeon and Jeonju) had the decreasing trend at the 0.05 significance level. 


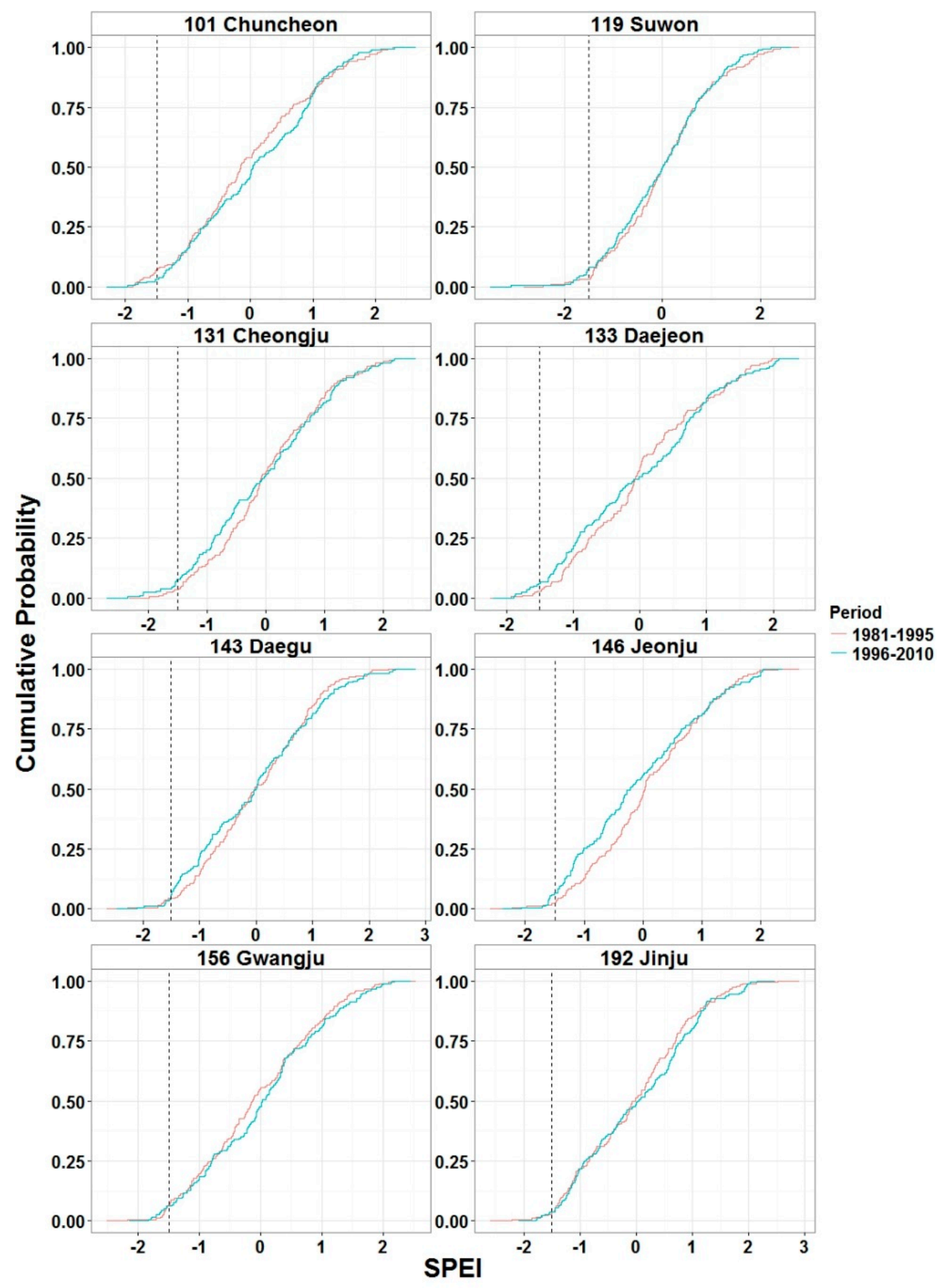

Figure 6. Cumulative probability curves of SPEI_pm for different regions 
Table 5. The results of Mann-Kendall (MK) trend test for SPEI_th and SPEI_pm

\begin{tabular}{|c|c|c|c|c|c|c|c|}
\hline \multirow{2}{*}{ SPEIs } & \multirow{2}{*}{ Regions } & \multirow{2}{*}{ Stations (No.) } & \multicolumn{5}{|c|}{ Z score } \\
\hline & & & DJF & MAM & JJA & SON & Annual \\
\hline \multirow{8}{*}{ SPEI_th } & \multirow{4}{*}{ Central } & Chuncheon (101) & 0.17 & 0.00 & 1.59 & -1.03 & 0.43 \\
\hline & & Suwon (119) & -0.25 & -0.36 & 1.59 & -1.30 & -0.32 \\
\hline & & Cheongju (131) & -0.36 & 0.03 & 0.68 & $-2.37^{*}$ & -0.79 \\
\hline & & Daejeon (133) & 0.22 & 0.13 & 0.51 & $-2.46^{*}$ & -0.43 \\
\hline & \multirow{4}{*}{ Southern } & Daegu (143) & 0.06 & -0.36 & -0.38 & $-2.30^{*}$ & -0.96 \\
\hline & & Jeonju (146) & -0.16 & -1.25 & 0.72 & $-3.65^{*}$ & -2.00 \\
\hline & & Gwangju (156) & 1.25 & 0.37 & 1.35 & $-2.39^{*}$ & -0.14 \\
\hline & & Jinju (192) & 0.17 & 0.79 & 0.17 & -1.38 & 0.25 \\
\hline \multirow{8}{*}{ SPEI_pm } & \multirow{4}{*}{ Central } & Chuncheon (101) & 0.11 & 0.63 & 1.78 & -0.38 & 1.32 \\
\hline & & Suwon (119) & -1.32 & -0.17 & 1.75 & -1.11 & -0.32 \\
\hline & & Cheongju (131) & -0.96 & 0.13 & 0.91 & -1.68 & -0.36 \\
\hline & & Daejeon (133) & -0.33 & -0.24 & 0.69 & -2.25 & -0.75 \\
\hline & \multirow{4}{*}{ Southern } & Daegu (143) & -0.23 & -0.21 & -0.03 & -1.35 & -0.64 \\
\hline & & Jeonju (146) & -0.80 & -1.61 & 0.88 & -3.55 & -2.28 \\
\hline & & Gwangju (156) & 0.99 & 0.37 & 1.52 & -1.88 & 0.14 \\
\hline & & Jinju (192) & 1.14 & 0.75 & 0.19 & -0.99 & 0.57 \\
\hline
\end{tabular}

\section{Conclusions}

The drought affects over a wide area spatially and socially. In addition it is vague about when is the beginning of drought. Accordingly, it is difficult to set the drought management plan. Several studies have been performed for quantifying the drought severity using drought index.

In this study, the drought characteristics such as duration, severity, and intensity at 8 stations were analyzed using the SPEI from 1981 to 2010. The SPEI is the representative drought index and it considers both precipitation and evapotranspiration which is the essential factor for evaluating crop growth. In this study, the SPEI was divided into SPEI_th and SPEI_pm depending on ETo equation such as Thornthwaite and FAO Penman-Monteith, respectively.

As the results of the drought intensity, the SPEI_pm identified drought more intensive rather than SPEI_th even if the same climate data were given. In particular, the cumulative curves of monthly SPEI_pm in two periods (1981-1995 and 1996-2010) showed that the severe drought happened frequently for 30 years.

We also analyzed the trends of time-series SPEIs using MK test. The increasing trend of SPEIs was shown on fall season, and the cumulative probability that SPEI_pm is below -1.5 was also significantly increased. These results indicated that the frequency of severe drought was increased from 1981 to 1990.

In recent research, climate change affects to aggregate severe drought, and the increase of temperature causes the loss of evapotranspiration. Accordingly, the analysis of drought trends could be useful for coping with agricultural drought under climate change condition. 
Acknowledgments: This work was supported by Korea Institute of Planning and Evaluation for Technology in Food, Agriculture, Forestry and Fisheries(IPET) through Agri-Bio industry Technology Development Program, funded by Ministry of Agriculture, Food and Rural Affairs(MAFRA)(313018-3).

Author Contributions: Seungjong Bae proposed the basic idea of the research. Sanghyun Lee and Seunghwan Yoo performed the numerical simulation. The manuscript was written by Seungjong Bae with the contribution of Sanghyun lee and Taegon Kim.

Conflicts of Interest: The authors declare no conflict of interest.

\section{References}

1. Allen, R.G.; Pereira, L.S.; Raes, D.; Smith, M. Crop evapotranspiration-Guidelines for computing crop water requirements-FAO Irrigation and drainage paper 56. FAO, Rome. 1998, 300(9), D05109.

2. Dai, A. Drought under global warming: a review. Wiley Interdisciplinary Reviews: Climate Change. 2011, 2(1), 45-65.

3. Dracup, J.A.; Lee, K.S.; Paulson, E.G. On the statistical characteristics of drought events. Water Resour. Res. 1980, 16(2), 289-296.

4. Dubrovsky, M; Svoboda, M.D.; Trnka, M.; Hayes, M.J.; Wilhite, D.A.; Zalud, Z.; Hlavinka, P. Application of relative drought indices in assessing climate change impacts on drought conditions in Czechia. Theor Appl Climatol. 2009, 96, 117-155.

5. González, J.; Valdés, J.B. New drought frequency index: Definition and comparative performance analysis. Water Resources Research, 2006, 42(11).

6. Hayes, M.J.; Svoboda, M.D.; Wilhite, D.A.; Vanyarkho, O.V. Monitoring the 1996 drought using the standardized precipitation index. Bull. Amer. Meteor. Soc. 1999, 80, 429-438.

7. Heim, R.R. A review of twentieth-century drought indices used in the United States. Bull. Amer. Meteor. Soc. 2002, 83, 1149-1165.

8. Jensen, M.E.; Burman, R.D.; Allen, R.G. Evapotranspiration and irrigation water requirements. ASCE. 1990.

9. Jeung, S.J.; Sung, J.H.; Kim, B.S. Change projection of extreme indices using RCP climate change scenario. Journal of the Korean Water Resources Association. 2013, 46(11), 1089-1101. (In Korean)

10. Kendall M.G. Rank Correlation Methods. Griffin: London. 1975.

11. Korea rural community corporation (KRC). Mitigation history of Drought. 2001.

12. Kim, B.S.; Sung, J.H.; Kang, H.S.; Cho, C.H. Assessment of drought severity over South Korea using standardized precipitation evapotranspiration index (SPEI). Journal of the Korean Water Resources Association. 2012, 45(9), 887-900. (In Korean)

13. Kim, B.S.; Sung, J.H.; Lee, B.H.; Kim, D.J. Evaluation on the impact of extreme droughts in South Korea using the SPEI and RCP8.5 climate change scenario. Journal of Korean Society of Hazard Mitigation. 2013, 13(2), 97-109. (In Korean)

14. Kim, H.K.; Jang, T.I.; Im, S.J.; Park, S.W. Estimation of irrigation return flow from paddy fields considering the soil moisture. Agricultural water management. 2009, 96(5), 875-882.

15. Korea Meteorological Administration (KMA). Understanding of climate change and application of climate change scenarios. National Institute of Meteorological Research, Seoul, South Korea. 2010. (In Korean)

16. Koutroulis, A.G.; Vrochidou, A.-E.K.; Tsanis, I.K. Spatiotemporal characteristics of meteorological 
drought for the island of Crete. J. Hydrometeorol. 2011, 12 (2), 206-226.

17. Kwak, J.W.; Lee, S.D.; Kim, Y.S.; Kim, H.S. Return period estimation of droughts using drought variables from standardized precipitation index. Journal of the Korean Water Resources Association. 2013, 46(8), 795805. (In Korean)

18. Loukas, A.; Vasiliades, L.; Tzabiras, J. Climate change effects on drought severity. Advances in Geosciences. 2008, 17(17), 23-29.

19. Mann H.B. Nonparametric tests against trend. Econometrica. 1945, 13, 245-259.

20. Mavromatis, T. Drought index evaluation for assessing future wheat production in Greece, Int. J. Climatol. 2007, 27, 7, 911-924.

21. Mishra, A.K.; Singh, V.P. A review of drought concepts. J. Hydrol. 2010, 391, 202-216.

22. Nam, W.H.; Hayes, M.J.; Wilhite, D.A.; Tadesse, T.; Svoboda, M.D. ; Knutson, C.L. Drought management and policy based on risk assessment in the context of climate change. Magazine of the Korean Society of Agricultural Engineers. 2014, 56(2), 2-15. (In Korean)

23. Nam, W.H.; Yoo, S.H.; Jang, M.W.; Choi, J.Y. Application of meteorological drought indices for North Korea. Journal of the Korean Society of Agricultural Engineers. 2008, 50(3), 3-15. (In Korean)

24. Rim, C.S.; Kim, S.Y. Climate aridity/humidity characteristics in Seoul according to changes in temperature and precipitation based on RCP 4.5 and 8.5. Journal of the Korean Water Resources Association. 2014, 47(5), 421-434. (In Korean)

25. Rossi, G. Drought mitigation measures: a comprehensive framework. In: Voght, J., Somma, F. (Eds.), Drought and Drought Mitigation in Europe. Kluwer Academic Publishers. 2000, 233-246.

26. So, J.M.; Sohn, K.H.; Bae, D.H. Estimation and assessment of bivariate joint drought index based copula functions. Journal of the Korean Water Resources Association. 2014, 47(2), 171-182. (In Korean)

27. Svoboda, M.D.; et al. The drought monitor. Bull. Amer. Meteor. Soc. 2002, 83, 1181-1190.

28. Thornthwaite, C. W. An approach toward a rational classification of climate. Geographical review. 1948, 5594.

29. Van der Schrier, G.; Jones, P.D.; Briffa, K.R. The sensitivity of the PDSI to the Thornthwaite and PenmanMonteith parameterizations for potential evapotranspiration. Journal of Geophysical Research: Atmospheres. 2011, 1984-2012.

30. Vicente-Serrano, S.M.; Beguería, S.; López-Moreno, J.I. A multiscalar drought index sensitive to global warming: the standardized precipitation evapotranspiration index. Journal of Climate. 2010, 23(7), 16961718.

31. Vrochidou, A.E.; Tsanis, I.K.; Grillakis, M.G.; Koutroulis, A.G. The impact of climate change on hydrometeorological droughts at a basin scale. Journal of Hydrology. 2013, 476, 290-301.

32. Wang, W.; Van Gelder, P.H.A.J.M.; Vrijling, J.K. Trend and stationarity analysis for streamflow processes of rivers in western Europe in the 20th century. In Proceedings: IWA International Conference on Water Economics, Statistics, and Finance Rethymno. 2005, 810.

33. Wilhite, D.A. Drought as a natural hazard: Concepts and definitions. Drought: A Global Assessment, D.A. Wilhite, Ed., Routledge. 2000, 3-18.

34. Wilhite, D.A.; Glantz, M.H. Understanding the drought phenomenon: The role of definitions. Water Int. 1985, 10, 111-120.

35. Wilhite, D.A.; Svoboda, M.D; Hayes, M.J. Understanding the complex impacts of drought: a key to enhancing drought mitigation and preparedness. Water Resources Management. 2007, 21, 763-774.

36. World Meteorological Organization. Drought and agriculture. WMO Tech. Note 138, Report of the CAgM Working Group on the Assessment of Drought, Geneva, Switzerland. 1975, 127. 
37. Yevjevich, V. An Objective Approach to Definitions and Investigations of Continental Hydrologic Drought. Hydrology Paper, 1967, No. 23, Colorado State Univ., Fort Collins, Colo.

38. Yoo, J.Y.; Choi, M.H.; Kim, T.W. Spatial analysis of drought characteristics in Korea using cluster analysis. Journal of the Korean Water Resources Association. 2010, 43(1), 15-24. (In Korean).

39. Yoo, J.Y.; Song, H.Y.; Kim, T.W.; Ahn, J.H. Evaluation of short-term drought using daily standardized precipitation index and ROC analysis. Journal of the Korean Society of Civil Engineers. 2013, 33(5), 1851-1860. (In Korean)

40. Yoon, S.K.; Cho, J.P.; Moon, Y.I. Non-parametric low-flow frequency analysis using RCPs scenario data: a case study of the Gwangdong storage reservoir, Korea. Journal of the Korean Society of Civil Engineers. 2014, 34(4), 1125-1138. (In Korean)

(C) 2016 by the authors; licensee Preprints, Basel, Switzerland. This article is an open access article distributed under the terms and conditions of the Creative Commons by Attribution (CC-BY) license (http://creativecommons.org/licenses/by/4.0/). 